\title{
MODEL ANGKA PARTISIPASI SEKOLAH JENJANG SMA SEDERAJAT DI PROVINSI BALI
}

\author{
Ni Luh Gede Widiadnyani ${ }^{1}$, Ni Luh Putu Suciptawati ${ }^{2}$, Made Susilawati ${ }^{3}$ \\ ${ }^{1}$ Program Studi Matematika, Fakultas MIPA - Universitas Udayana [Email: nlgdwidiadnyani@gmail.com] \\ ${ }^{2}$ Program Studi Matematika, Fakultas MIPA - Universitas Udayana [Email: suciptawati@ unud.ac.id] \\ ${ }^{3}$ Program Studi Matematika, Fakultas MIPA - Universitas Udayana [Email: mdsusilawati@unud.ac.id] \\ ${ }^{\S}$ Corresponding Author
}

\begin{abstract}
Each distritcs in Bali Province has an uneven high school enrollment rate. The lowest of high school enrollment rate is Bangli Regency in 2012 at 41,99 percent and the highest is Klungkung Regency in 2014 at 91,49 percent. The purpose of this work is to modeling and determine the significant factors that affect the high school enrollment rate in Bali Province by applying panel data regression. The results show the suitable model is fixed effect model (FEM) that is fixed individual effect model and significant affect by HDI, the percentage of poverty, and gini ratio.
\end{abstract}

Keywords: Bali Province, high school enrollment rate, panel data regression

\section{PENDAHULUAN}

Terciptanya sumber daya manusia yang berkualitas tidak terlepas dari pengaruh aspek pendidikan. Melalui pendidikan, diharapkan mampu mengembangkan potensi diri sesuai kemampuan dimiliki. Indikator keberhasilan pendidikan pada suatu wilayah di Indonesia disebut angka partisipasi sekolah (APS). Upaya pemerintah Indonesia dalam memajukan pendidikan adalah melalui wajib belajar 12 tahun, dengan jenjang tertinggi yaitu SMA sederajat pada seluruh wilayah di Indonesia. Salah satunya di Provinsi Bali.

Provinsi Bali termasuk satu diantara 34 provinsi di Indonesia yang memiliki data angka partisipasi sekolah jenjang SMA sederajat yang berfluktuasi, khususnya tahun 2010-2017. Penurunan drastis angka partisipasi sekolah jenjang SMA sederajat di Provinsi Bali terjadi di Kabupaten Klungkung pada tahun 2016 sebesar 15,3 persen dari tahun sebelumnya (BPS Provinsi Bali, 2017). Secara keseluruhan, angka partisipasi sekolah jenjang SMA sederajat tertinggi ditemukan di Kabupaten Klungkung pada tahun 2014 sebesar 91,49 persen dan terendah ditemukan di Kabupaten Bangli pada tahun 2012 sebesar 41,99 persen. Hal tersebut mengindikasi bahwa terjadi ketidakmerataan angka partisipasi sekolah jenjang SMA sederajat di Provinsi Bali.
Penelitian sebelumnya terkait angka partisipasi sekolah (APS) dilakukan oleh Fellovy (2013) mengenai faktor-faktor yang memengaruhi angka partisipasi sekolah jenjang pendidikan SMA dan SMP di Indonesia. Risetnya menyimpulkan bahwa angka partisipasi sekolah jenjang pendidikan SMA dan SMP di Indonesia signifikan dipengaruhi oleh indeks pembangunan manusia (IPM), rasio gini, dan indeks harga konsumen. Penelitian juga dilakukan oleh Sari (2013) dalam menentukan faktor-faktor yang memengaruhi angka partisipasi sekolah di Provinsi Jawa Barat. Faktor-faktor yang digunakan seperti angka melek huruf, rasio jumlah sekolah terhadap penduduk usia sekolah, rasio jumlah guru terhadap jumlah penduduk usia sekolah, persentase sumber air minum tidak bersih, persentase angkatan kerja, persentase kemiskinan, pendapatan asli daerah (PAD), produk domestik regional bruto (PDRB), dan persentase desa. Penelitian lainnya dilakukan oleh Rahmatin \& Soejoto (2017), risetnya menyimpulkan bahwa tingkat kemiskinan dan jumlah sekolah signifikan memengaruhi angka partisipasi sekolah di Kota Surabaya.

Berdasarkan penelitian sebelumnya mengenai faktor-faktor yang memengaruhi angka partisipasi sekolah (APS), peneliti ingin mengetahui pengaruh indeks pembangunan 
manusia (IPM), persentase kemiskinan (HCI$\mathrm{P} 0)$, rasio gini (GR), angka melek huruf (AMH), dan jumlah sekolah (JS) terhadap angka partisipasi sekolah (APS) jenjang SMA sederajat di Provinsi Bali pada tahun 2010 - 2017. Data angka partisipasi sekolah jenjang SMA sederajat di Provinsi Bali pada penelitian ini berupa data panel yang terdiri dari dimensi waktu (tahun) dan dimensi objek (kabupaten). Oleh karena itu, analisis yang digunakan adalah analisis regresi data panel.

Analisis regresi data panel adalah analisis regresi yang didasarkan pada data panel untuk mengamati hubungan variabel terikat dengan satu atau lebih variabel bebas (Gujarati \& Porter, 2009). Menurut Greene (2012), terdapat tiga macam model dalam analisis regresi data panel, yaitu common effect model (CEM), fixed effect model (FEM), dan random effect model (REM). Budinirmala dkk (2018) mengunakan regresi data panel dalam memodelkan kemiskinan penduduk Provinsi Bali. Risetnya menunjukkan bahwa model terbaik adalah FEM dengan fixed time effect.

Adapun tujuan dalam penelitian ini adalah untuk mengetahui model regresi data panel yang cocok digunakan untuk memodelkan angka partisipasi sekolah jenjang SMA sederajat di Provinsi Bali pada tahun 2010-2017 dan mengetahui faktor-faktor yang berpengaruh signifikan.

\section{METODE PENELITIAN}

\subsection{Jenis dan Sumber Data}

Jenis data yang digunakan dalam penelitian ini adalah data sekunder dari tahun 2010 hingga 2017 pada masing-masing kabupaten/kota di Provinsi Bali. Data penelitian ini bersumber dari publikasi Badan Pusat Statistik Provinsi Bali.

\subsection{Variabel Penelitian}

Variabel dependen $\left(Y_{i t}\right)$ yang digunakan adalah angka partisipasi sekolah (APS) jenjang SMA sederajat usia 16-18 tahun dan variabel independen yang digunakan adalah indeks pembangunan manusia (IPM) $\left(X_{1 i t}\right)$, persentase kemiskinan $\left(X_{2 i t}\right)$, rasio gini $\left(X_{3 i t}\right)$, angka melek huruf $\left(X_{4 i t}\right)$, dan jumlah sekolah $\left(X_{5 i t}\right)$.

\subsection{Tahapan Analisis}

Analisis data dalam penelitian ini menggunakan software $\mathrm{R}$ i386 3.4.3. Berikut merupakan tahapan analisis dalam penelitian ini:
1. Mengestimasi model regresi data panel yang terdiri dari common effect model (CEM), fixed effect model (FEM), dan random effect model (REM).

\section{a. Common effect model (CEM)}

Common Effect Model mengasumsikan bahwa intersep dan slope tetap pada unit cross section dan time series. Menurut Baltagi (2005), estimasi parameter dalam model ini dapat menggunakan metode OLS (ordinary least square). Secara umum, persamaan modelnya sebagai berikut:

$$
\begin{gathered}
Y_{i t}=\alpha+\sum_{k=1}^{5} \beta_{k} X_{k i t} \\
+u_{i t} ; \\
i=1,2,3, \ldots, 9 ; t=2010,2011, \ldots, 2017
\end{gathered}
$$

dengan $\alpha$ adalah intersep, $K$ adalah jumlah variabel independen, $\beta$ adalah slope berukuran ( $\mathrm{K} \times 1)$, dan $u$ adalah slope berukuran $(\mathrm{N} \times \mathrm{T}) \times 1$.

\section{b. Fixed effect model (FEM)}

Dalam Gujarati \& Porter (2009), fixed effect model (FEM) adalah model yang mengasumsikan bahwa intersep bersifat tidak konstan, sementara koefisien slope diasumsikan tetap antarunit cross section. Secara umum, persamaan modelnya sebagai berikut:

$$
\begin{gathered}
Y_{i t}=\boldsymbol{D} \alpha_{i}+\sum_{k=1}^{5} \beta_{k} X_{k i t} \\
\quad+u_{i t} ; \\
i=1,2,3, \ldots, 9 ; t=2010,2011, \ldots, 2017
\end{gathered}
$$

dengan $\alpha$ adalah intersep, $K$ adalah jumlah variabel independen, $\beta$ adalah slope berukuran (Kx 1), $\boldsymbol{D}$ adalah matriks variabel dummy dan $u$ adalah error berukuran $(\mathrm{N} \times \mathrm{T}) \times 1$.

Fixed effect model (FEM) dipisahkan menjadi 2 yaitu fixed individual effect model dan fixed time effect model.

1. Fixed individual effect model

$$
\begin{aligned}
& Y_{i t} \\
& =\sum_{r=1}^{9} D_{r t} \alpha_{r} \\
& +\sum_{k=1}^{5} \beta_{k} X_{i t} \\
& +u_{i t} ;
\end{aligned}
$$

$i, r=1,2,3, \ldots, 9 ; t=2010,2011, \ldots, 2017$ dengan $D_{r t}=1$ jika $r=i, D_{r t}=0$ jika $r \neq i$.

2. Fixed time effect model 


$$
\begin{aligned}
& Y_{i t} \\
& =\sum_{s=1}^{8} D_{i s} \alpha_{s} \\
& +\sum_{k=1}^{5} \beta_{k} X_{i t} \\
& +u_{i t} ;
\end{aligned}
$$

$i=1,2,3, \ldots, 9 ; t, s=2010,2011, \ldots, 2017$ dengan $D_{i s}=1$ jika $s=t, D_{i s}=0$ jika $s \neq t$.

\section{c. Random effect model (REM)}

Intersep pada random effect model (REM) diasumsikan sebagai variabel acak. Estimasi parameter pada REM menggunakan metode GLS (generalized least square). Secara umum, persamaan modelnya sebagai berikut:

$$
\begin{gathered}
Y_{i t}=\alpha_{0}+\sum_{k=1}^{5} \beta_{k} X_{k i t} \\
\quad+w_{i t} ; \\
i=1,2,3, \ldots, 9 ; t=2010,2011, \ldots, 2017
\end{gathered}
$$

dengan $\alpha$ adalah intersep, $K$ adalah jumlah variabel independen $\beta$ adalah slope berukuran $(\mathrm{K} \times 1)$ dan $w$ adalah galat (error) gabungan terdiri dari $e_{i}+u_{i t}$.

2. Melakukan pemilihan model regresi data panel menggunakan uji Chow dan uji Hausman.

3. Melakukan pengujian signifikansi parameter terhadap model regresi data panel yang terpilih.

\begin{tabular}{|c|c|c|c|c|}
\hline Variabel & Parameter & $\begin{array}{c}\text { Nilai } \\
\text { Estimasi }\end{array}$ & $\begin{array}{l}\text { Nilai } t \\
\text { hitung }\end{array}$ & Nilai $p$ \\
\hline Intersep & $\alpha$ & $-98,65$ & $-2,97$ & 0,004 \\
\hline IPM & $\beta_{1}$ & 2,51 & 5,09 & $3,1 \times 10^{-6}$ \\
\hline HCI-P0 & $\beta_{2}$ & 3,74 & 3,13 & 0,002 \\
\hline GR & $\beta_{3}$ & 85,81 & 3,14 & 0,002 \\
\hline $\mathrm{AMH}$ & $\beta_{4}$ & $-0,53$ & $-1,54$ & 0,126 \\
\hline JS & $\beta_{5}$ & $-0,26$ & $-2,15$ & 0,034 \\
\hline \multicolumn{4}{|c|}{ Nilai $F$-hitung } & 11,165 \\
\hline \multicolumn{4}{|c|}{ Nilai $p$} & $8 \times 10^{-8}$ \\
\hline \multicolumn{4}{|r|}{ Nilai $R^{2}$} & 0,4582 \\
\hline
\end{tabular}

4. Menginterpretasikan hasil yang diperoleh.

\section{HASIL DAN PEMBAHASAN}

\subsection{Common Effect Model (CEM)}

Hasil estimasi model CEM disajikan pada Tabel 1. sebagai berikut:

Tabel 1. Estimasi common effect model

Sumber: data diolah, 2019

\subsection{Fixed Effect Model}

Dalam estimasi fixed individual effect model terdapat variabel dummy individu yang dalam penelitian ini berupa kabupaten/kota, seperti Jembrana, Tabanan, Badung, Gianyar, Klungkung, Bangli, Karangasem, Buleleng, dan Denpasar. Sementara, dalam fixed time effect

\begin{tabular}{|c|c|c|c|c|}
\hline Variabel & $\begin{array}{c}\text { Parame } \\
\text { ter }\end{array}$ & $\begin{array}{c}\text { Nilai } \\
\text { Estimasi }\end{array}$ & $\begin{array}{l}\text { Nilai } t \\
\text { hitung }\end{array}$ & Nilai $p$ \\
\hline Jembrana & $\alpha_{1}$ & $-310,99$ & $-6,73$ & $8 \times 10^{-9}$ \\
\hline Tabanan & $\alpha_{2}$ & $-324,09$ & $-6,77$ & $7 \times 10^{-9}$ \\
\hline Badung & $\alpha_{3}$ & $-328,91$ & $-6,76$ & $7,2 \times 10^{-9}$ \\
\hline Gianyar & $\alpha_{4}$ & $-319,53$ & $-6,69$ & $9,4 \times 10^{-9}$ \\
\hline Klungkung & $\alpha_{5}$ & $-296,76$ & $-6,53$ & $1,7 \times 10^{-8}$ \\
\hline Bangli & $\alpha_{6}$ & $-292,44$ & $-6,84$ & $5,2 \times 10^{-9}$ \\
\hline Karangasem & $\alpha_{7}$ & $-289,34$ & $-6,61$ & $1,3 \times 10^{-8}$ \\
\hline Buleleng & $\alpha_{8}$ & $-316,59$ & $-6,30$ & $4,2 \times 10^{-8}$ \\
\hline Denpasar & $\alpha_{9}$ & $-360,55$ & $-6,89$ & $4,4 \times 10^{-9}$ \\
\hline IPM & $\beta_{1}$ & 4,81 & 5,09 & $3,9 \times 10^{-6}$ \\
\hline HCI-P0 & $\beta_{2}$ & 3,05 & 2,18 & 0,032 \\
\hline GR & $\beta_{3}$ & 70,86 & 3,00 & 0,003 \\
\hline $\mathrm{AMH}$ & $\beta_{4}$ & $-0,001$ & $-0,002$ & 0,997 \\
\hline JS & $\beta_{5}$ & 0,406 & $-0,72$ & 0,469 \\
\hline \multicolumn{4}{|c|}{ Nilai $F$-hitung } & 18,522 \\
\hline \multicolumn{4}{|c|}{ Nilai $p$} & $5,9 \times 10^{-11}$ \\
\hline \multicolumn{4}{|c|}{ Nilai $R^{2}$} & 0,6149 \\
\hline
\end{tabular}
model terdapat variabel dummy waktu berupa tahun yaitu dari tahun 2010 hingga 2017.

Estimasi fixed individual model dan fixed

\begin{tabular}{|c|c|c|c|c|}
\hline Variabel & $\begin{array}{c}\text { Parame } \\
\text { ter }\end{array}$ & $\begin{array}{c}\text { Nilai } \\
\text { Estimasi }\end{array}$ & $\begin{array}{l}\text { Nilai } t \\
\text { hitung }\end{array}$ & Nilai $p$ \\
\hline 2010 & $\alpha_{1}$ & $-44,91$ & $-1,30$ & 0,198 \\
\hline 2011 & $\alpha_{2}$ & $-42,99$ & $-1,30$ & 0,196 \\
\hline 2012 & $\alpha_{3}$ & $-40,85$ & $-1,26$ & 0,212 \\
\hline 2013 & $\alpha_{4}$ & $-38,16$ & $-1,14$ & 0,256 \\
\hline 2014 & $\alpha_{5}$ & $-30,68$ & $-0,90$ & 0,367 \\
\hline 2015 & $\alpha_{6}$ & $-31,19$ & $-0,91$ & 0,365 \\
\hline 2016 & $\alpha_{7}$ & $-30,91$ & $-0,91$ & 0,365 \\
\hline 2017 & $\alpha_{8}$ & $-31,56$ & $-0,92$ & 0,359 \\
\hline IPM & $\beta_{1}$ & 2,19 & 4,67 & $1,7 \times 10^{-5}$ \\
\hline HCI-P0 & $\beta_{2}$ & 2,50 & 1,95 & 0,054 \\
\hline GR & $\beta_{3}$ & 51,02 & 1,43 & 0,155 \\
\hline $\mathrm{AMH}$ & $\beta_{4}$ & $-0,79$ & $-2,64$ & 0,010 \\
\hline JS & $\beta_{5}$ & $-0,16$ & $-1,58$ & 0,117 \\
\hline \multicolumn{4}{|c|}{ Nilai $F$-hitung } & 8,341 \\
\hline \multicolumn{4}{|c|}{ Nilai $p$} & $5,1 \times 10^{-6}$ \\
\hline \multicolumn{4}{|c|}{$\begin{array}{ll} & \text { Nilai } R^{2}\end{array}$} & 0,4141 \\
\hline
\end{tabular}
time effect model disajikan pada Tabel 2 dan Tabel 3.

Tabel 2. Estimasi fixed individual effect model

Sumber: data diolah, 2019

Tabel 3. Estimasi fixed time effect model

Sumber: data diolah, 2019 


\subsection{Random Effect Model} Tabel 4

Hasil estimasi model REM disajikan pada

Tabel 4. Estimasi Random Effect Model

\begin{tabular}{|c|c|c|c|c|}
\hline Variabel & $\begin{array}{c}\text { Paramet } \\
\text { er }\end{array}$ & $\begin{array}{c}\text { Nilai } \\
\text { Estimasi }\end{array}$ & $\begin{array}{l}\text { Nilai } t \\
\text { hitung }\end{array}$ & Nilai $p$ \\
\hline Intersep & $\alpha$ & $-187,27$ & $-4,47$ & $3 \times 10^{-6}$ \\
\hline IPM & $\beta_{1}$ & 3,00 & 3,97 & 0,0001 \\
\hline HCI-P0 & $\beta_{2}$ & 4,09 & 2,87 & 0,005 \\
\hline GR & $\beta_{3}$ & 86,03 & 3,37 & 0,001 \\
\hline AMH & $\beta_{4}$ & 0,06 & 0,12 & 0,898 \\
\hline JS & $\beta_{5}$ & $-0,38$ & $-1,45$ & 0,150 \\
\hline \multicolumn{4}{|c|}{ Nilai $F$-hitung } & 11,629 \\
\hline \multicolumn{4}{|c|}{ Nilai $p$} & $4,4 \times 10^{-8}$ \\
\hline \multicolumn{4}{|r|}{ Nilai $R^{2}$} & 0,4683 \\
\hline
\end{tabular}

Sumber: data diolah, 2019

\subsection{Pemilihan model regresi data panel}

Pemilihan model regresi data panel dapat dilakukan menggunakan uji Chow dan uji Hausman.

\section{a. Uji Chow}

Uji Chow mempertimbangkan keberadaan intersep masing-masing kabupaten/kota. Hipotesis yang digunakan dalam uji Chow sebagai berikut:

$H_{0}: \alpha_{1}=\alpha_{2}=\cdots=\alpha_{9}$ (tidak terdapat

perbedaan intersep pada masing-masing

kabupaten/kota).

$H_{1}$ : minimal terdapat sepasang $\alpha_{j} \neq \alpha_{r}$

(minimal terdapat sepasang kabupaten/ kota

yang memiliki intersep berbeda).

Berdasarkan perhitungan, diperoleh bahwa nilai $=1,8 \times 10^{-7} \quad<\alpha(0,05), \quad$ sehingga $H_{0}$ ditolak. Oleh karena itu, model yang cocok adalah fixed individual effect model yang merupakan bagian dari FEM.

\section{b. Uji Hausman}

Pada uji Hausman fixed effect model dibandingkan dengan random effect model (Greene, 2012). Namun, dalam uji Hausman terlebih dahulu dilakukan pemilihan model FEM dengan memerhatikan nilai koefisien determinasi $\left(R^{2}\right)$ pada fixed individual effect model dan fixed time effect model yang terdapat pada Tabel 2 dan Tabel 3. Nilai koefisien determinasi $\left(R^{2}\right)$ fixed time effect model $(41,41 \%)<$ nilai koefisien determinasi $\left(R^{2}\right)$ fixed individual effect model (61,49\%), sehingga pada uji Hausman fixed individual effect model akan dibandingkan dengan random effect model.
Hipotesis yang digunakan adalah:

$$
\begin{array}{ll}
H_{0}: E\left(w_{j t} \mid X_{j t}\right)=0 & \text { (REM konsisten) } \\
H_{1}: E\left(w_{j t} \mid X_{j t}\right) \neq 0 & \text { (REM tidak konsisten) }
\end{array}
$$

Berdasarkan perhitungan, diperoleh bahwa nilai $p=3,02 \times 10^{-5}<\alpha(0,05)$, sehingga $H_{0}$ ditolak. Dengan demikian model yang cocok dalam penelitian ini adalah fixed individual effect model.

\subsection{Pengujian Signifikansi}

Dalam penelitian ini, terdapat dua pengujian signifikansi yaitu secara simultan dan parsial Dengan memerhatikan Tabel 2 secara simultan diperoleh bahwa nilai $p=5,9 \times 10^{-11}<\alpha(0,05)$ maka keputusannya adalah $H_{0}$ ditolak. Hal tersebut berarti terdapat variabel independen dalam model yang berpengaruh terhadap variabel dependen.

Secara parsial, dengan memerhatikan Tabel 2 terdapat tiga variabel independen yang signifikan yaitu indeks pembangunan manusia (IPM), persentase kemiskinan, dan rasio gini.

\subsection{Interpretasi Hasil}

Persamaan fixed individual effect model sebagai berikut:

$$
\begin{aligned}
Y_{j t}= & \alpha_{j}+4,81 X_{1 j t}+3,05 X_{2 j t}+70,86 X_{3 j t}-0,001 X_{4 j t} \\
& +0,406 X_{5 j t}+u_{j t} ; \\
& i=1,2, \ldots, 9 ; t=2010,2011, \ldots, 2017
\end{aligned}
$$

Nilai intersep masing-masing kabupaten disajikan pada Tabel 5.

Tabel 5. Nilai Intersep Setiap Kabupaten/Kota

\begin{tabular}{|l|l|}
\hline Parameter & Nilai intersep \\
\hline$\alpha_{\text {Jembrana }}$ & $-310,99$ \\
\hline$\alpha_{\text {Tabanan }}$ & $-324,09$ \\
\hline$\alpha_{\text {Badung }}$ & $-328,91$ \\
\hline$\alpha_{\text {Gianyar }}$ & $-319,53$ \\
\hline$\alpha_{\text {Klungkung }}$ & $-296,76$ \\
\hline$\alpha_{\text {Bangli }}$ & $-292,44$ \\
\hline$\alpha_{\text {Karangasem }}$ & $-289,34$ \\
\hline$\alpha_{\text {Buleleng }}$ & $-316,59$ \\
\hline$\alpha_{\text {Denpasar }}$ & $-360,55$ \\
\hline
\end{tabular}

Sumber: data diolah, 2019

Merujuk pada fixed individual effect model diperoleh nilai koefisien determinasi sebesar 0,6149. Dapat diartikan bahwa kelima prediktor yang digunakan mampu menjelaskan APS jenjang SMA sederajat sebesar 61,49 persen dan sisanya dijelaskan oleh prediktor lain yang tidak disertakan dalam model. 
Secara parsial diperoleh bahwa indeks pembangunan manusia (IPM), persentase kemiskinan, dan rasio gini signifikan memengaruhi angka partisipasi sekolah jenjang SMA sederajat di Provinsi Bali.

Memerhatikan bahwa IPM berhubungan dengan pembangunan sumber daya manusia yang saling berkaitan dengan aspek pendidikan. Riset Destilunna \& Zain (2015) menunjukkan bahwa peningkatan APS dan IPM dapat memperluas jangkauan masyarakat dalam menempuh pendidikan. Sementara persentase kemiskinan dan rasio gini merupakan dua faktor dalam aspek ekonomi yang dalam pencapaiaannya didasarkan pada aspek pendidikan.

\section{KESIMPULAN DAN SARAN}

\subsection{Kesimpulan}

Model yang cocok dalam penelitian ini adalah fixed effect model (FEM) yaitu fixed individual effect model dengan koefisien determinasi sebesar 61,49 persen.

Faktor-faktor yang signifikan berpengaruh terhadap angka partisipasi sekolah (APS) jenjang SMA sederajat di Provinsi Bali adalah indeks pembangunan manusia (IPM), persentase kemiskinan, dan rasio gini.

\subsection{Saran}

Dengan keterbatasan kemampuan variabel prediktor dalam penelitian ini menjelaskan angka partisipasi sekolah jenjang SMA sederajat, diharapkan penelitian selanjutnya dapat menemukan variabel prediktor lain yang lebih berpeluang dalam meningkatkan angka partisipasi sekolah jenjang SMA sederajat, sebagai misal anggaran BOS dan pendapatan perkapita.

Memerhatikan nilai koefisien determinasi yang diperoleh, model dalam penelitian ini dianggap belum baik. Diharapkan pada penelitian selanjutnya, dapat menggunakan metode lain yang kemungkinan dapat memperbaiki model.

\section{DAFTAR PUSTAKA}

Baltagi, B. H. 2005. Econometrics Analysis of Panel Data (3rd ed). Chicester, England: John Wiley \& Sons Ltd.

BPS Provinsi Bali. 2017. Provinsi Bali dalam Angka 2017. Bali: BPS Provinsi Bali.

Budinirmala, K., Suciptawati, P., Jayanegara, K., \& Kencana, E. N. 2018. Memodelkan Kemiskinan Penduduk Provinsi Bali dengan Regresi Data Panel. E-Jurnal Matematika, 7(3), 219-225.

Destilunna, F. G., \& Zain, I. 2015. Pengaruh dan Pemetaan Pendidikan, Kesehatan, serta UMKM terhadap Indeks Pembangunan Manusia di Jawa Timur Menggunakan Regresi Panel dan Biplot. Jurnal Sains \& Seni ITS, 5(2).

Fellovy, A. 2013. Analisis Faktor-Faktor yang Mempengaruhi Angka Partisipasi Sekolah Pada Jenjang Pendidikan Sekolah Menengah Pertama (SMP) dan Sekolah Menengah Atas (SMA) Sederajat di Indonesia (Analisis Data Panel 2008-2011). Thesis (Diploma). Sumatera Barat: Fakultas Ekonomi Universitas Andalas.

Greene, W. H. 2012. Econometric Analysis (7th ed.). New York: Prentice Hall.

Gujarati, D. N., \& Porter, D. C. 2009. Basics Econometrics (5th ed.). New York: The McGrow-Hill.

Rahmatin, U. Z., \& Soejoto, P. A. 2017. Pengaruh Tingkat Kemiskinan dan Jumlah Sekolah terhadap Angka Partisipasi Sekolah di Kota Surabaya. Jurnal Pendidikan Ekonomi Manajemen dan Keuangan, 1(2), 127-140.

Sari, R. C. 2013. Penentuan Faktor-Faktor yang Mempengaruhi Angka Partisipasi Sekolah dengan Pendekatan Regresi Spasial (Studi Kasus: 26 Kabupaten/kota di Provinsi Jawa Barat Tahun 2011). Skripsi. Bogor: Departemen Statistika Fakultas MIPA Institut Pertanian Bogor. 